\title{
VOLUME CREEP TESTING MACHINE
}

\section{ABBAS AGHAJANIKALKHOURAN}

Research scholar Mechanical Science and Engineering, Huazhong University of Science and Technology, Wuhan / China

ABSTRACT
Volume creep testing machine designed to test cylindrical rock salt specimen exposed by petroleum pressure in
different pressures and temperatures. The volume creep testing machinecomprises: two cells each of which included
some parts like main cell, stabilizer system, insulator layer, heater, support layer, check valve and rubber sleeve.
The main cells have responsibility of retaining petroleum pressure and temperature and applying them to the specimen.
A tank; to storage the fluid and transmit it with pressure into the cells through pipes. The tank consists of a hydraulic
jack and six check valves as petroleum inlets and outlets. Ultrasonic testing systems; they used for measuring the
thickness and strain of rock salt frequently. Each ultrasonic testing system comprises two dual element transducers and a
memory to storage data. A thermometer and one pressure gauge which installed inside of the inner cell.
KEYWORDS: Creep Testing Machine, Rock Salt Specimen, Design a Creep Testing Machine \& Ultrasonic Measuring

Received: Nov 15, 2017; Accepted: Dec 05, 2017; Published: Jan 17, 2018; Paper Id.: IJMPERDFEB201872

\section{INTRODUCTION}

In mechanical engineering, creep is viewed as the tendency of solid materials to deform permanently under the impact of mechanical stress as well as consequential strain. It could be happened as a result of a longterm exposure to high levels of stress which are still below the yield strength of the material. This phenomenon occurs in all temperatures in which it is more severe in materials as a subject to a high level of heat for a long time that results in increasing when they are near their melting points.

To this respect, the rate of strain is a function of the material properties including physical and mechanical, time, temperature, and the applied structural load. Depending on the magnitude of the applied stress and its duration of time, the deformation can be so large that a component can no longer perform its duty. As an example, creep of a centrifuge turbine blade causes the blade to conflict with the chamber or other blades which results in the defect of the blade.

By applying pressure (stress) an initial strain appeared which brings about Stress-strain modulus. The material starts deforming with time as well as failure that is caused by yielding. In the primary region the creep rate decreases very fast. After that, it closes to a fix position called the stage of secondary creep resulted in a rapid increase as well as fracture. During the secondary stage range of the strain is approximately constant. The above-mentioned phenomenon which happens under loading with time is considered as creeping. Nest stage that is called tertiary creep is in conjunction with increasing very fast of creep rate and it is continue until fracturing.

Creep testing machines are a practical means to measure long-term mechanical behavior of rocks. Its process usually involves a multistage differential stress. Stress applied at all levels of the process must be 
strictly kept constant in order to guaranty the test reliability. The test usually lasts up to a few months.

Over the last fifty years creep test has changed to a controversial issue especially when it comes to related testing methods, machines and their vital parts. The importance of this affair getting more highlight in majors such as mechanics, civil, metallurgy and so forth. One fundamental factor in laboratories experiments is instruments. Experiments' devices must be designed and manufactured such that amount of errors inclined towards zero which it will cause having reliable and accurate data and results.

Fixtures with the responsibility of keeping sample balance during different experiments like uniaxial, biaxial and triaxial tests. Components that use fluid for applying pressure comprises a vital part that their responsibility is transfer the fluid inside of the cell and maintain the desirable pressure inside of the cell during the experiment. And measuring devices which should fulfil their duty in a precise way in a harsh condition (high pressure and temperature) are some of the most significant issues that should be regarded in an appropriate and practical design.

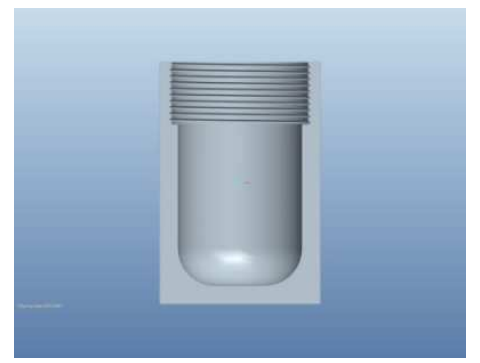

Procuring these purposes could be hard and complicated due to a significant reason; these types' experiments usually are along with high level of pressure and temperature that can cause difficulties. All in all each of previous creep testing machines designed in order to use in a particular system. Some of them were elaborated and some of them simple.

\section{Design}

\section{Main cell (ASTM A516)}

This part according to the circumstances in which during experiment take place should be designed. The responsibilities of inner cell (body and lid) are bearing stresses which brought about petroleum pressure up to over 200MPa and temperature about 80 ' $\mathrm{C}$ so that we will be able to incur about 200MPa pressure on the whole sides of our cylindrical specimen and keep the specimen and rubber sleeve balance in the center.

Body

Regarding to responsibilities of body and inner lid as well as stabilizer system should be the most strength parts of this machine. Because the body and lid of inner cell must settle stabilizer system (clamps, rods and protrusions), rubber sleeve and specimen inside of itself, however, its dimension should be proportional to the other dimensions.

The body of inner cell will be made from appropriate steel with $15 \mathrm{~mm}$ thickness. The height of body is $195 \mathrm{~mm}$ and its radius is $65 \mathrm{~mm}$ so that height of chamber for petroleum is $150 \mathrm{~mm}$ and radius of that is $50 \mathrm{~mm}$. During upper $50 \mathrm{~mm}$ from the inside of the body it is threaded to locate the lid of cell.

\section{Lid}

Regarding to responsibilities of body and lid of inner cell these two parts and stabilizer system should be the most strength parts of this machine. Because the body and lid of inner cell must settle stabilizer system (clamps, rods, and 
protrusions), rubber sleeve, and specimeninside of itself, its dimension should be proportional to the other dimensions.

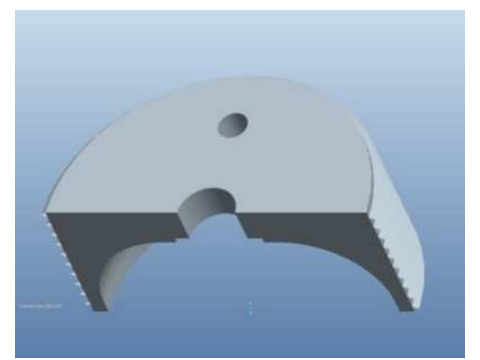

The lid of inner cell will be made from appropriate steel with $15 \mathrm{~mm}$ thickness for topand $5 \mathrm{~mm}$ for wall. The height of lid is $50 \mathrm{~mm}$ and its radius is $55 \mathrm{~mm}$. During the whole outer, lateral surface of lid will be threaded. Moreover, from the inside at the center of surface wewill make a hole with $30 \mathrm{~mm}$ diameter and $2 \mathrm{~mm}$ height for locating and fixing the movement part of check valve.

\section{GLASS-CERAMIC INSULATOR}

Temperature preservation of fluid in which flow inside of inner body is prevented fromheating travel is obligation of insulator. Insulator is included from two parts that these two parts puttogether to coat and cover the inner cell body completely. Therefore, insulator should be designedaccording to the circumstances during experiment and inner cell dimensions. Moreover, its design andquality of material should allow it to tolerate intermediate level of flexibility. Due to this reason wewould rather use glass-ceramic material from one famous company like Aremco.

\section{Body}

This part of insulator should cover from the lid of inner body while having contactwith outer body and lid. Body of insulator should be a container which has $215 \mathrm{~mm}$ height and $75 \mathrm{~mm}$ outer radius with $10 \mathrm{~mm}$ thickness. In addition, the best location for heater is inside ofthe insulator in order to have direct contact with inner cell.

\section{Lid}

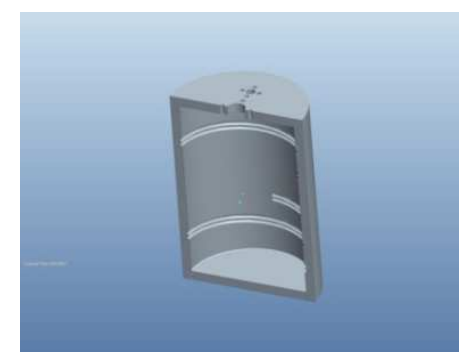

This part of insulator should be covered at the bottom of inner body while having contact with outer body. This part has $10 \mathrm{~mm}$ height and $65 \mathrm{~mm}$ radius in order to be fixed in the body of insulator.

\section{OUTER CELL (AISI 1040 SUPPORT)}

This part should be designed according to the circumstances which happened during experiment. Outer cell or support should cover the insulator during the experiment. If we use an outer layer made of steel during analysis the machine in Ansys software, then we can suppose that the inner cell would be fix during the experiment. The cell body should decrease tolerating stress. We will use AISI 1040 steel with 10mm thickness that has high load-bearing.

Note: the magnitude of pressure that outer body should suffer is less than pressure that inner body should. 


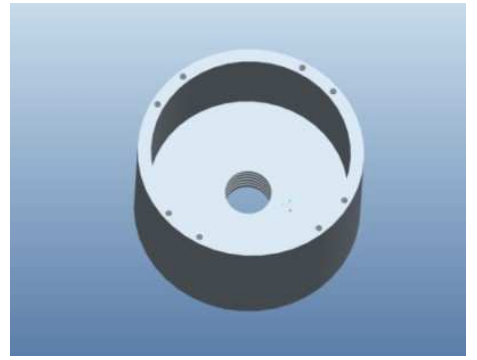

Due to the fact that the outer cell body must settle inner cell inside of itself, thus, its dimension should be proportional to the dimension of inner cell. The outer cell or supportconsists of two separate parts including upper and lower connected via some bolds. Moreover, due to the fact that we want to use P-wave propagation to be measured in our experiment, two holes should be created for two transducers (sources and detectors) that one of them will be made in the lateral surface of upper body and another one at the bottom of lower support.

\section{UPPER SUPPORT (AISI 1040)}

Upper part should be covered from top of the insulator about the middle of insulator and it should have holes for checking valves and one chamber for horizontal transducer in the middle of specimen. The upper support has $142.5 \mathrm{~mm}$ height and $85 \mathrm{~mm}$ radius with $10 \mathrm{~mm}$ thickness.

\section{LOWER SUPPORT (AISI 1040)}

Lower part should be covered from bottom of the insulator to the middle of insulator and it should be connect to upper support by bolts. The lower support has $110.8 \mathrm{~mm}$ height and $170 \mathrm{~mm}$ diameter with $10 \mathrm{~mm}$ lateral thickness and $28.3 \mathrm{~mm}$ bottom thickness. This part should have one space for vertical transducer located in the bottom and at the center.

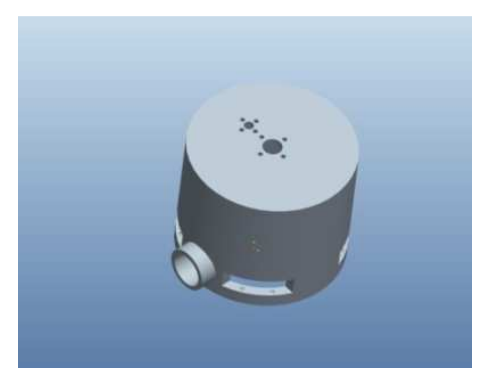

\section{RUBBER SLEEVE (WITHOUT HOLES)}

This rubber sleeve will have been used to realize four substantial aims;

- $\quad$ Prevent specimen from falling apart as a result of excessive pressure.

- Rubber sleeve inhibits fluid have contact with sample. It should coat the specimen and stick it.

- It should have reliable strength which will not be torn due to high level of stress.

- It should settle the specimen inside of itself. Therefore, the dimension of rubber sleeve mustbe proportional to the sample size. It should have $101 \mathrm{~mm}$ height and $51 \mathrm{~mm}$ diameter with $0.5 \mathrm{~mm}$ thickness.

\section{DRILLED RUBBER SLEEVE}

Drilled rubber sleeve has four essential obligations. Therefore, its design should be compatible with its duties. 
- $\quad$ Prevent specimen from breaking down as a result of high level of pressure.

- Drilled rubber sleeve ought to provide an opportunity fluid has contact with specimen.

- It should have reliable strength which will not be torn due to excessive pressure.

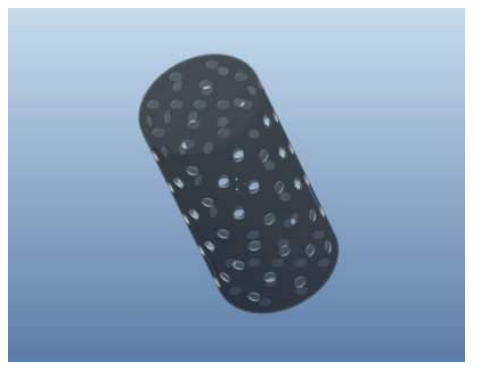

- It should settle the specimen inside of itself. Therefore, the dimension of rubber sleeve mustbe proportional to the sample size. It has $101 \mathrm{~mm}$ length and $51 \mathrm{~mm}$ diameter with some holes in its whole lateral surfaces and top and bottom.

\section{SPECIMEN}

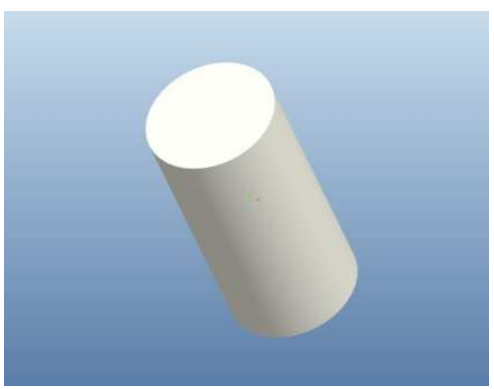

Our specimen is a cylindrical salt rock with 100mm height and 50mm diameter.

\section{TANK}

Tank has been comprised of body, hydraulic jack, and check valves. The capacity oftank should be as twice as capacity of each cell.

\section{Body}

This part shall be designed so that accommodates hydraulic jack in itself. Accordingly, two check valves as petroleum outlets in downward of body and four as oil inlets which two of them in upward and two of them in downward will be located. Tank is a cell (chamber) with $23 \mathrm{~mm}$ thickness, $346 \mathrm{~mm}$ and $50 \mathrm{~mm}$ inner height and radius respectively.

\section{Hydraulic Jack}

Hydraulic jack is connected to the hydraulic pump and causes transmission of power from hydraulic pump to fluid and consequently push down the petroleum. It should exit oil from tank by outlets check valves that it results in having pressurized petroleum in two smaller cells and keep the pressure stable during the experiment. Hydraulic jack has $120 \mathrm{mmlength}$ and two diameters; sizes of smaller diameter that is pertaining to the upper part and bigger one that is used to push the petroleum respectively are $25 \mathrm{~mm}$ and $100 \mathrm{~mm}$. Moreover, thickness of pusher part is $20 \mathrm{~mm}$. 


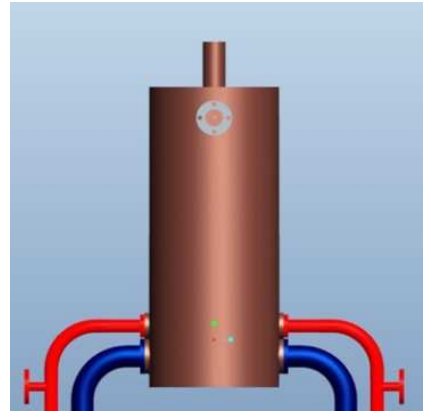

\section{PIPES}

The transmission of fluid into and out of tank is the obligation of pipes. It should have contact with check valves. Their design, size, and material should be chosen so that has tolerance of high level of pressure. Pipes which are used to convey petroleum from tank to cells have $102.5 \mathrm{~mm}$ length and $25 \mathrm{~mm}$ diameter with $2.5 \mathrm{~mm}$ thickness. Pipes that transmit oil from cells to the tank have $166.25 \mathrm{~mm}$ length and $15 \mathrm{mmdiameter}$ with $2.5 \mathrm{~mm}$ thickness. Pipes that responsibility of transmitting the petroleum to the tank are two straight pipes with $105 \mathrm{~mm}$ length, $25 \mathrm{~mm}$ diameter and $2.5 \mathrm{~mm}$ thickness.

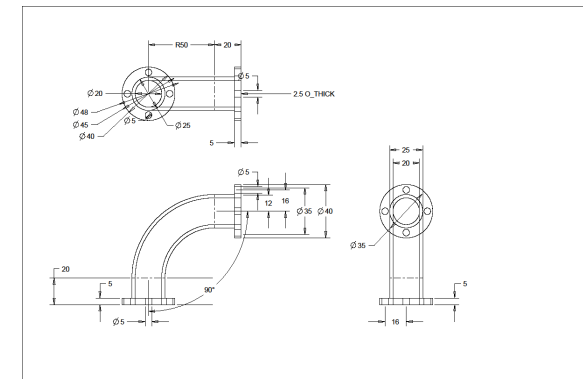

\section{Stabilizer System}

Stabilizer system comprises several parts that will be explained in the following paragraphs. It is a set of two separate clamps each of which comprised four L shape clip (corner shape) which connected to the rods from one side and specimen from another side. They have responsibility of fixing specimen in the center of the cell without any displacements. The design shall be in such a way that specimen can be placed and fixed in the center and have an appropriate thickness. Moreover, it should be made from strength material to resist high level of pressure, stress, and temperature.

L shape clip (corner shape) has two faces with $7.5 \mathrm{~mm}$ length and $10 \mathrm{~mm}$ width to contact with sample and about $5 \mathrm{~mm}$ thickness.

\section{Protrusions}

These parts are two chamfered protrusions that should be welded to the inside of the body and lid of cell as a link between cell and rods to increase strength of system.

\section{Rods}

There are sixteen rods including eight bigger and eight smaller that will be separated two by two. The smaller should slide in bigger. They can move via eight springs which are located behind the smaller rods inside of bigger rods and create eight sets of rods. Four of them will be connected to the upper protrusion and the others to the lower by welding. Rods have the responsibility of connecting protrusions to L shape clips. The design of rods is in a way that they will be 
vigor to resist high level of pressure, stress, and temperature (to do that we designate $5 \mathrm{~mm}$ diameter of rod). Therefore, the material which will be used for making them is important. In order to create rod we should divide it to three parts; bigger rod, smaller rod, and spring.

\section{Bigger Rod}

Bigger rod has responsibility of keeping the smaller rod and let it slide inside via the spring which is located inside of the bigger rod behind of the smaller rod. Bigger rod should be vigor to resist to high level of pressure, stress, and temperature.

Note: with this setting the diameter of rod is $20 \mathrm{~mm}$ and its length is $20 \mathrm{~mm}$ that has enough strength.

\section{Smaller Rod}

The duty of smaller rod is connecting the bigger one to the hook (fillet shape). It can slideinside of the bigger rod and has connection with spring to move and follow the specimenwhen shrinkage happens. This part has $15 \mathrm{~mm}$ length and $5 \mathrm{~mm}$ diameter to have enough strength.

\section{Spring}

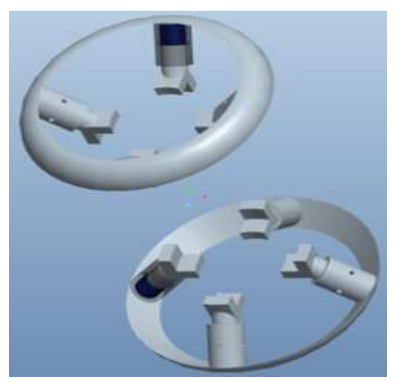

The spring of clamp should be located inside of the bigger so that to connect protrusion from one side and small rod from another side. This spring pushes the smaller rod to guide and move hook toward the sample with $10 \mathrm{~mm}$ length and 1.5 pitch values during specimen shrinkage.
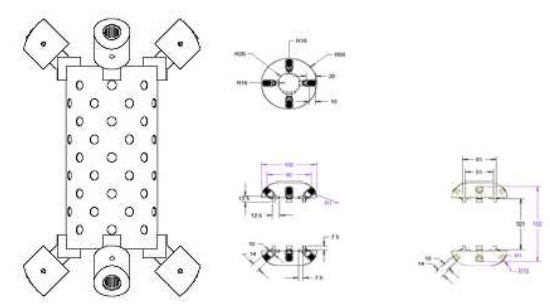

\section{CHECK VALVE}

Check valve or one-way valve is a device for controlling the flow of fluid. Actuallywe will use check valves to prevent fluid from returning the fluid. In this system eight checkvalves will be improvised so that two in each cell as petroleum inlets and four in tank that twoof them as petroleum outlets and two of them as inlets. The check valves designed as inlethave $20 \mathrm{~mm}$ diameter while those work as outlet have just $10 \mathrm{~mm}$ diameter. These devicesshould be designed so that to estimate tolerance fluid at high level of pressure and stress. Ourcheck valve consists of three separate parts such as body of check valve, spring, and ballsystem. 


\section{Body of Check valve}

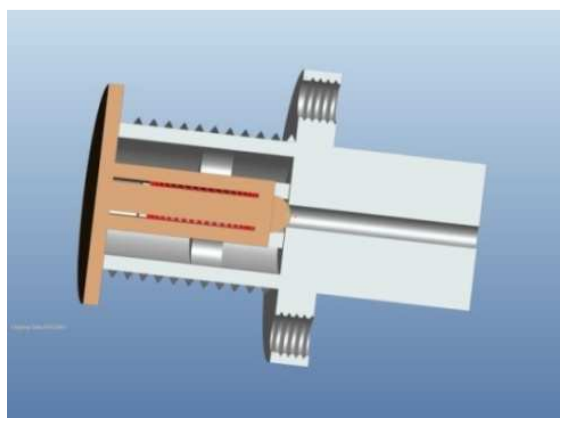

Body of check valve will be utilized as a guide for fluid flow and should keep springand ball together. Body of check valve has contact with lid of inner cell (ASTM A516 grade70), insulator (glass-ceramic), support (AISI 1040) and pipe (ASTM A420 grade WPL6) incells and with body of tank and pipe in tank system.

When fluid comes from inlet, the ball is pushed back by fluid pressure. Thus, at thistime petroleum can have flow from upper and lower ducts and continues its way by spanningfrom those four oval-shaped holes and is achieved inside of the cell. In this way spring pushesthe ball system, however, the shape of the ball system would thrust in hole of inner cell.

For designing this part, we need to make a chamber that can keep spring and ballsystem while they have a horizontally movement, one piece to contact with cell components, and one piece to contact with pipe.

\section{Spring}

For designing spring it is essential to consider the dimension of check valve body andball as well as using standard material. These springs have $10 \mathrm{~mm}$ length and $1.5 \mathrm{~mm}$ diameter.

\section{Ball System}

For designing spring it is essential to consider the dimension of check valve body andball as well as using standard material. This part comprises of two parts which will be madeseparately and then will have been welded to each other. These parts are semi-sphere andlever that stacked to a cylinder and this cylindrical shape will be fixed inside of inner lid.

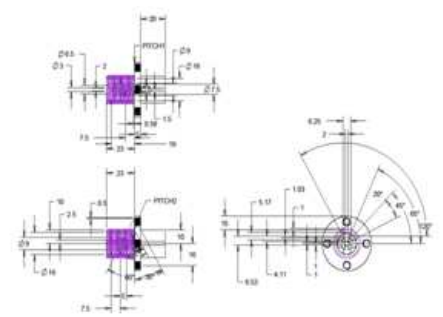

\section{ANSYS}

\section{Geometry}

The first analysis will be done for inner cell and inner lid (ASTM A516 grade70 (485))

- In analyzing inner cell in order to alleviate analysis we would rather use 2D shape andanalysis. Therefore, we sketch a $\mathrm{C}$ shape with $195 \mathrm{~mm}$ height and $65 \mathrm{~mm}$ radius that has $15 \mathrm{~mm}$ thickness. 
- There are two circumcircular arcs with about $30 \mathrm{~mm}$ length.

The second analysis designated for bigger rod, smaller rod, and clamp (hook).

- Import assembles of these three parts.

- $\quad$ Merge faces.

- $\quad$ Eliminating the redundant fragments and make a unit part from bigger rod, smaller rod andhook (in explanation)

- Make bigger rod and its bottom (included two faces) which will be fixed, as a part.

Note: only one of eight parts of stabilizer system will be analyze by ANSYS.

\section{Mechanical}

At first we should attribute the materials to the components in "geometry" followed by"material" as well as "assignment".

- $\quad$ Inner cell, ASTM A516 grade 70 (485)

- $\quad$ Stabilizer system, structural steel

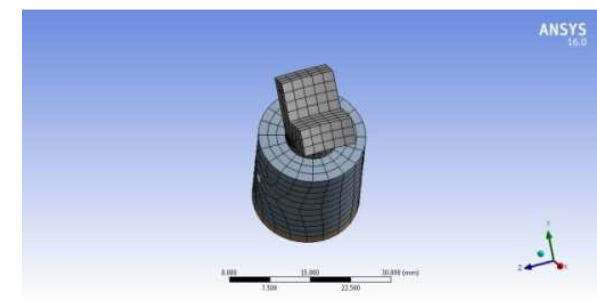

\section{Steady-State Thermal}

MESH

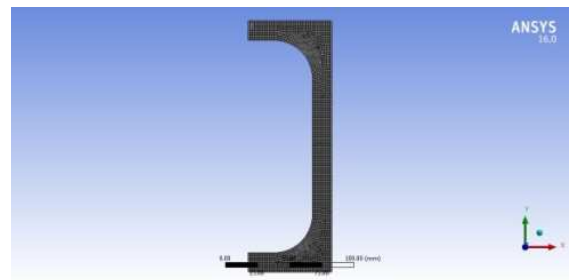

Mesh plays an important role in preparation model in order to have an accurateanalysis. Thus, mesh components are listed as follow:

- In order to mesh inner cell we will use one body with the size of $1.25 \mathrm{~mm}$ value for the wholeshape.

- In order to mesh clamp comprises of hook and smaller rod, Hex dominant method should be chosen. For size of the mesh $2 \mathrm{~mm}$ has been chosen.

- Multi zone method is appropriate for bigger rod its upper face is selected as manual source and three sections for sweep element. Upper and lower edges should be divided to twenty parts by using edge sizing. For size of the mesh $3 \mathrm{~mm}$ has been chosen.

- Last part is bottom of bigger rod that is a separate cylindrical shape in mesh step. Multi zone with manual source 
is an aptly method for meshing it. In addition, upper and lower edges should be divided like edges of bigger rod.

For size of the mesh $3 \mathrm{~mm}$ has been chosen.

According to the test condition in this level we impose from 0 to about 80 'Ctemperature to cell and stabilizer system before taking them to the nest stage.

To apply temperature;

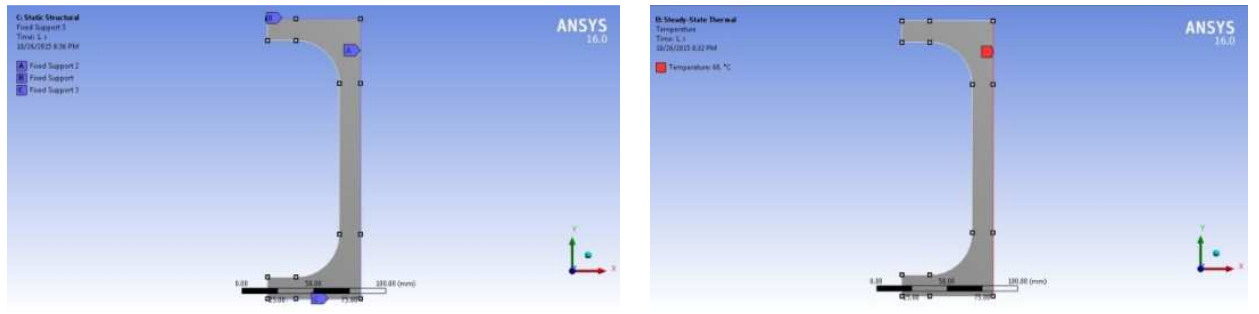

- In inner cell just one outer vertical edge selected.

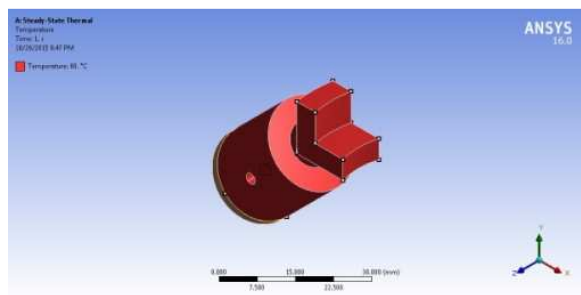

- In stabilizer system outer surfaces of bigger rod (except lower face), inner faces of biggerrod, bottom of smaller rod, outer faces of upper part of smaller rod, inside of the holes andall faces of hook which totally are equal to sixteen faces.

\section{Static Structure}

\section{Main Cell}

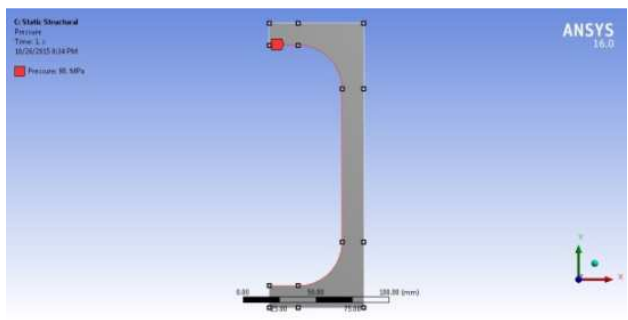

Load; choose five inner edges to apply 0 to 220MPa pressure.

Support; determine three outer edges (top, bottom and vertical) as fixed support.

\section{Stabilizer System}

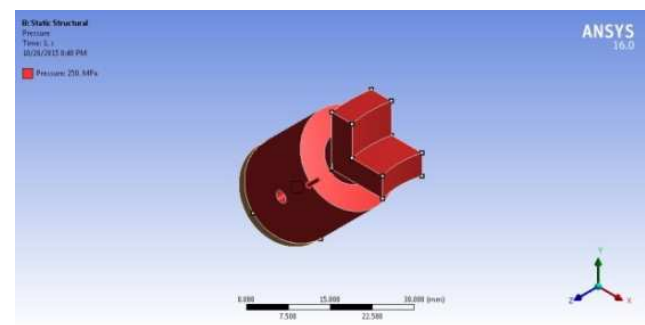


Load; select outer surfaces of bigger rod (except lower face), inner faces of bigger rod,bottom of smaller rod, outer faces of upper part of smaller rod, inside of the holes and allfaces of hook which totally are equal to sixteen faces to apply 0 to $220 \mathrm{MPa}$ pressure.

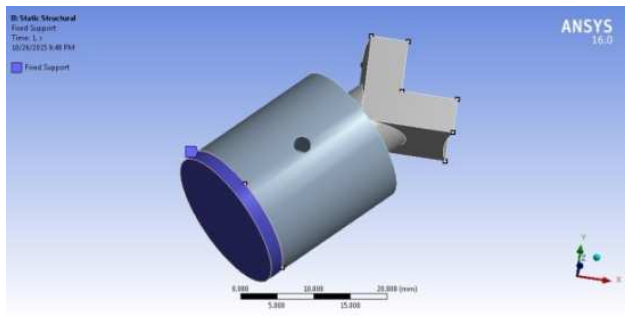

Support; outer lower face of bigger rod and its bottom selected as fixed support.

\section{MATLAB}

After receiving and analyzing the data from source and detectors we need to showthem as an acceptable and practical shape which it is as form of creep graph. Here I havewritten a program in MATLAB that can do some mathematical work on received data andthen display three separate graphs.

Creep graph pertaining to horizontal axis 2. Creep graphpertaining to vertical axis and 3. It is volume creep graph of specimen which has beenprocured from integration of first and second one.

clear;

clc;

Diameter $0=50$;

Height $0=100$;

Diameter $=[\mathrm{x}$ xxxxxxxxx $\mathrm{x}]$;

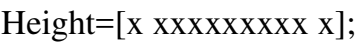

$p=[0: .1: 1]$

for $\mathrm{i}=1$ :length(p)

$\operatorname{CornV}(\mathrm{i})=\left(\left((\text { Diameter }(\mathrm{i}) / 2)^{\wedge} 2 *\right.\right.$ pi $*$ Height $\left.(\mathrm{i})\right)-$

$\left((\text { Diameter0/2 })^{\wedge} 2 * \mathrm{pi}^{*}\right.$ Height0) $) /(($ Diameter0/2)^2*pi*Height0);

CornD(i)=-(Diameter(i)-Diameter0)/Diameter0;

$\operatorname{CornH}(\mathrm{i})=-($ Height $(\mathrm{i})-$ Height 0$) /$ Height 0 ;

end

$\operatorname{subplot}(2,2,1)$

$\operatorname{plot}\left(\mathrm{p}, \operatorname{CornV},{ }^{\prime}-{ }^{*} \mathrm{~b}^{\prime}\right)$

title('Volume Creep')

xlabel('time(h)') 


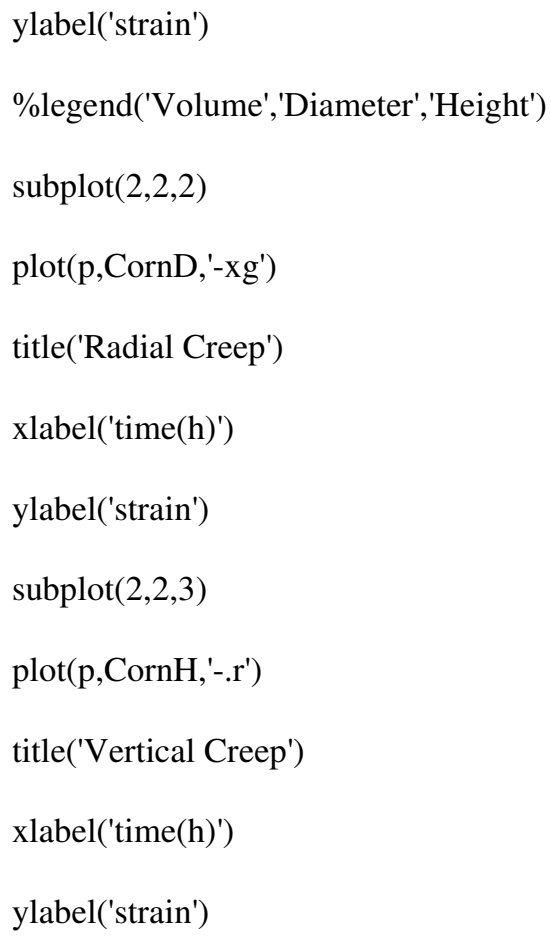

\section{Procedure of Experiment}

Machine can calculate volume of specimen simply and it is possible to process the rate of volume by comparing and deducting these numbers.

- The procedure of the experiment is starting by filling in the tank with fluid which is filled in straight upper pipes and check valves.

- $\quad$ To compressing fluid inside of the tank two methods were contrived;

Imposing the pressure on top surface of lever. Purring the oil causes this force. The oil is transmitted into the tank via another upper straight pipe and after check valve.

The second way is that, pushing the lever via one hydraulic jack from outside of the tank.

- Coming down the lever causes the petroleum behind of the cantilever were imposed and were left the tank from two lower check valves and pressured fluid will enter into the cells via curved pipes and check valves.

- Entering the pressured fluid into the cells will continue until cell filling and the desired pressure approaching (we can know the amount of pressure through pressure gauges which stacked on the specimen and wall of the cell). After filling the cells and closing the inlet by check valve, heater in which located around the cell starts to work and makes heating till the fluid and specimen will have got desired temperature (one thermometer is located on the specimen to measure temperature of sample).

- By incurring the heat and pressure, specimen starts changing. The vital point in this experiment is that, the specimen must not move from center of the cell. This aim materializes by utilizing an appropriate stabilizing system. Protrusions of stabilizer let us to have a strong weld and connect between stabilizer system and cell. Inside of each bigger rod, one spring contrived in order to be located behind of the smaller rod to push the smaller 
rod and hook toward specimen continually and prevent from separating between clamps and sample during the experiment. This strategy prevents from displacement of the sample.

- To measure strain of the rock salt in this experiment, ultrasonic method was contrived. In this method displacement of the points during the time will be measured through measuring the current location of the points. Sources start to send and transmit P-wave. This wave after encountering to each boundary of materials, mirrors and returns back.

The speeds of P-wave in different materials are determined $(\mathrm{V})$, during this experiment we count the time $(\Delta t)$. According to linear speed equation which is:

$$
\Delta x=V \Delta t
$$

Therefore, the location of each point at each moment will be procured. Consequently, by comparing the locations, we can measure thickness of specimen. By each propagating, we can determine the exact location of the points at a moment. To measure strain, source should send P-wave about 1000 times a second and detector should detect them in order to have more accurate results.

Note: The sine wave or sinusoid is a mathematical curve that describes a smooth repetitive oscillation. It is named after the function sine which is the graph. It occurs often in pure and applied mathematics, as well as physics, engineering, signal processing and many other fields. It's most basic form as a function of time $(t)$ is:

$$
y(t)=A \sin (2 \pi f t+\varphi)=A \sin (\omega t+\varphi)
$$

Where:

$A$ : the amplitude, the peak deviation of the function from zero.

$f$ : the ordinary frequency, the number of oscillations (cycles) that occur each second of time.

$\omega: 2 \pi f$, the angular frequency, the rate of change of the function argument in units of radians per second

$\varphi$ : the phase, specifies (in radians) where in its cycle the oscillation is at $t=0$.

- When $\varphi$ is non-zero, the entire waveform appears to be shifted in time by theamount $\varphi / \omega$ seconds. A negative value represents a delay, and a positive value represents an advance.

- Mathematically, the most basic wave is the (spatially) one-dimensional sine wave (or harmonic wave or sinusoid). The sine wave is important in physics because it retains its wave shape when added to another sine wave of the same frequency and arbitrary phase and magnitude. It is the only periodic waveform that has this property. This property leads to its importance in Fourier analysis and makes it acoustically unique. Therefore, our suggestion is sine wave for propagation in this machine.

We want to procure volume creep, Therefore, two sources and detectors will be contrived. One of them towards the vertical axis and another one horizontally. The former for measuring vertical strain of sample and the latter for measuring radial strain. The primary length and radius of sample is determined. So we can measure the volume of specimen by using volume formula for cylindrical shape that is: 
Volume $=\pi r^{2} \times \mathrm{h}$

We can write a program with MATLAB software in order to compute the volume of specimen in each moment and compare with the previous one and the first one and draw a graph so that strain vs. time. By this way we can have got the graph of strain rate vs. time or volume creep graph.

Results of Analysis in ANSYS for Inner Cell with Safety Factor 1.5

\begin{tabular}{|c|c|c|c|}
\hline $\begin{array}{c}\text { Temperature } \\
{ }^{C} \mathbf{C}\end{array}$ & $\begin{array}{c}\text { Minimum } \\
\text { Pressure Mpa }\end{array}$ & $\begin{array}{c}\text { Maximum } \\
\text { Pressure Mpa }\end{array}$ & $\begin{array}{c}\text { Product Design } \\
\text { Stress Mpa }\end{array}$ \\
\hline $22-25$ & - & 202.5 & 172.92 \\
\hline $25-30$ & - & 232 & 173.08 \\
\hline $30-35$ & - & - & - \\
\hline $35-40$ & - & - & - \\
\hline $40-45$ & - & - & - \\
\hline $45-49$ & - & - & - \\
\hline $49-53$ & 22 & - & 172.98 \\
\hline $53-60$ & 63.5 & - & 173.04 \\
\hline $60-65$ & 93 & - & 172.99 \\
\hline $65-70$ & 123 & - & 173.24 \\
\hline $70-75$ & 152.5 & - & 173.11 \\
\hline $75-80$ & 183 & - & 173.1 \\
\hline $80-85$ & 213.5 & - & \\
\hline $85-90$ & 244 & - & 173.2 \\
\hline
\end{tabular}

Results of Analysis in ANSYS for Inner Cell with Safety Factor 1.33

\begin{tabular}{|c|c|c|c|}
\hline $\begin{array}{c}\text { Temperature } \\
{ }^{6} \mathbf{C}\end{array}$ & $\begin{array}{c}\text { Minimum } \\
\text { Pressure Mpa }\end{array}$ & $\begin{array}{c}\text { Maximum } \\
\text { Pressure Mpa }\end{array}$ & $\begin{array}{c}\text { Product Design } \\
\text { Stress Mpa }\end{array}$ \\
\hline $20-25$ & - & 225 & 195.37 \\
\hline $25-30$ & - & 254 & 195.03 \\
\hline $30-35$ & - & - & - \\
\hline $35-40$ & - & - & - \\
\hline $40-45$ & - & - & - \\
\hline $45-50$ & - & - & - \\
\hline $50-53$ & - & - & 195.48 \\
\hline $53-60$ & 41 & - & 195.2 \\
\hline $60-65$ & 71 & - & 195.44 \\
\hline $65-70$ & 100.5 & - & 195.19 \\
\hline $70-75$ & 130.5 & - & 195.06 \\
\hline $75-80$ & 161 & - & 195.04 \\
\hline $80-85$ & 191.5 & - & 195.15 \\
\hline $85-90$ & 222 & - & \\
\hline
\end{tabular}

Results of Analysis in ANSYS for Stabilizer System with Safety Factor 1.5

\begin{tabular}{|c|c|c|c|}
\hline $\begin{array}{c}\text { Temperature } \\
{ }^{C} \mathbf{C}\end{array}$ & $\begin{array}{c}\text { Minimum } \\
\text { Pressure Mpa }\end{array}$ & $\begin{array}{c}\text { Maximum } \\
\text { Pressure Mpa }\end{array}$ & $\begin{array}{c}\text { Product Design } \\
\text { Stress Mpa }\end{array}$ \\
\hline $22-25$ & - & 159 & 166.2 \\
\hline $25-30$ & - & 172 & 166.31 \\
\hline $30-35$ & - & 184 & 166.43 \\
\hline
\end{tabular}




\begin{tabular}{|c|c|c|c|c|}
\hline \multicolumn{5}{|c|}{ Table: Contd., } \\
\hline $35-40$ & - & 198 & \multicolumn{2}{|c|}{166.54} \\
\hline $40-48$ & - & 218.5 & \multicolumn{2}{|c|}{166.4} \\
\hline $48-52$ & 24 & 229 & 166.31 & 166.6 \\
\hline $52-55$ & 47 & 236.5 & 166.35 & 166.34 \\
\hline $55-60$ & 86 & 249 & 166.52 & 165.91 \\
\hline $60-65$ & 126.5 & - & 166.39 \\
\hline $65-70$ & 168 & - & \multicolumn{2}{|c|}{166.44} \\
\hline $70-75$ & 211 & - & \multicolumn{2}{|c}{166.46} \\
\hline
\end{tabular}

Results of Analysis in ANSYS for Stabilizer System with Safety Factor 1.33

\begin{tabular}{|c|c|c|c|c|}
\hline Temperature 'C & $\begin{array}{c}\text { Minimum } \\
\text { Pressure Mpa }\end{array}$ & $\begin{array}{c}\text { Maximum } \\
\text { Pressure Mpa }\end{array}$ & \multicolumn{2}{|c|}{$\begin{array}{c}\text { Product Design } \\
\text { Stress Мpa }\end{array}$} \\
\hline $22-25$ & - & 178.5 & \multicolumn{2}{|l|}{187.63} \\
\hline $25-30$ & - & 191.5 & \multicolumn{2}{|l|}{187.74} \\
\hline $30-35$ & - & 204 & \multicolumn{2}{|l|}{187.3} \\
\hline $35-40$ & - & 217 & \multicolumn{2}{|l|}{187.42} \\
\hline $40-48$ & - & 238 & \multicolumn{2}{|l|}{187.82} \\
\hline $48-52$ & - & 248 & \multicolumn{2}{|l|}{187.48} \\
\hline $52-55$ & 21 & 255.5 & 187.33 & 187.22 \\
\hline $55-60$ & 59 & - & \multicolumn{2}{|l|}{187.67} \\
\hline $60-65$ & 99 & - & \multicolumn{2}{|l|}{187.14} \\
\hline $65-70$ & 139 & - & \multicolumn{2}{|l|}{187.37} \\
\hline $70-75$ & 180 & - & \multicolumn{2}{|l|}{187.65} \\
\hline $75-80$ & 223 & - & \multicolumn{2}{|l|}{187.4} \\
\hline
\end{tabular}
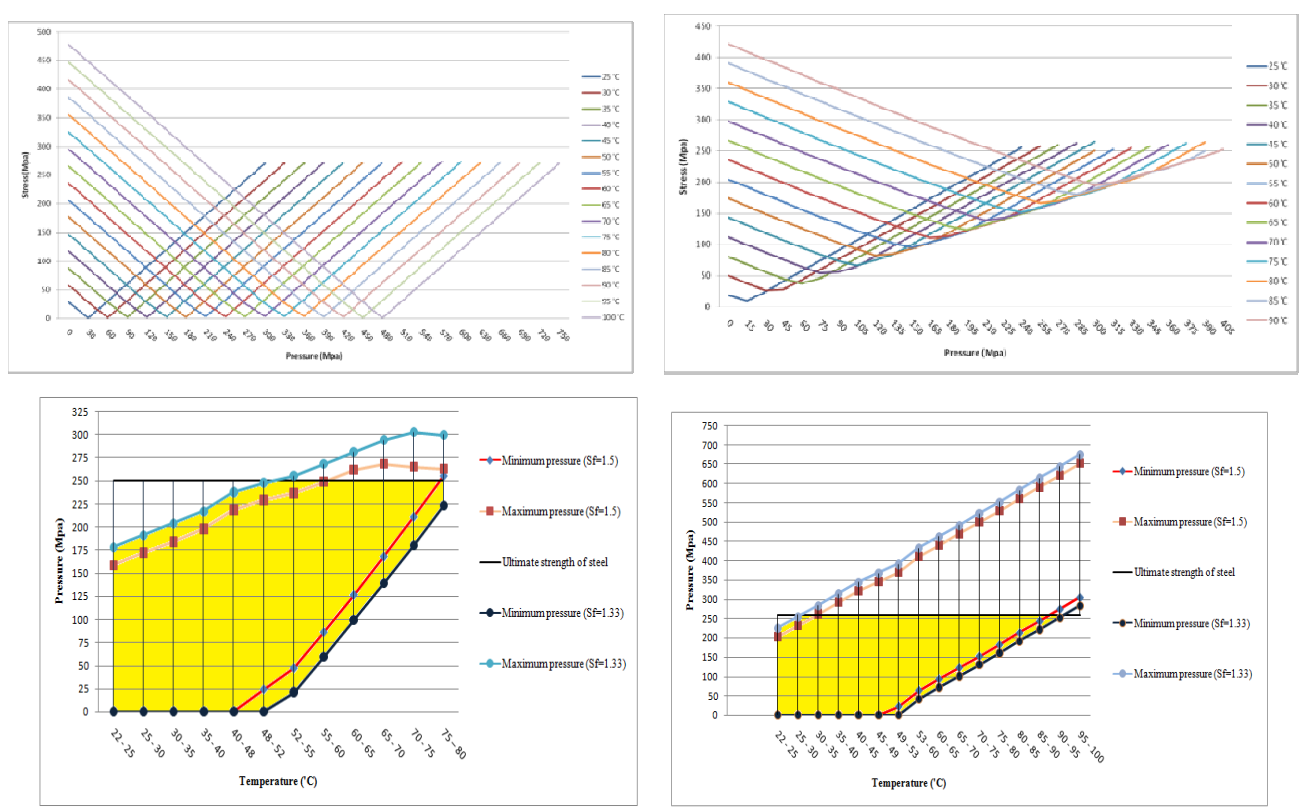


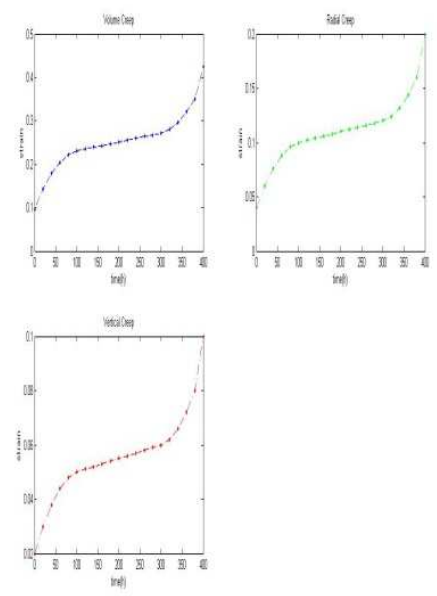

\section{CONCLUSIONS}

To sum up, in this thesis an experiment and means have been designed to measure volume creep of a cylindrical rock salt specimen exposed by petroleum pressure. The volume creep testing machine which designed by Pro Engineer and analyzed with ANSYS software comprised of three main parts such as three separate cylindrical cell which connects and forms as a unit, as well as two smaller cylindrical cells equipped by stabilizer system to keep specimens stable at the center, a heater for generating heat and making desired temperature, and a layer of insulator to prevent cells from wasting and changing temperature. Accordingly, each of these smaller cells has two check valves to inlet and outlet petroleum. Additionally, there are two rubber sleeves to cover specimens to prevent samples from collapsing; one without any pores for a cell and one with holes for another cell. Accordingly, last part is a bigger chamber which will be used as tank of petroleum. It consists of one hydraulic jack in order to leave pressurized fluid from its two oil outlets. There are two strains measuring systems each of which would be installed on cylinder machine that consists of primary wave maker and wave detector for sending and propagating the wave and some instruments that are useful such as: pressure sensors and thermometers.

By comparison between results of cell and stabilizer system in ANSYS, according to the safety factors working limitations for volume creep testing machine procured. For fulfilling creep experiments by this means with safety factor of 1.5, from 22 to $48{ }^{\prime} \mathrm{C}$ no need to impose initial pressure and just there are limitation of maximum pressures that are from 159 to $218.5 \mathrm{Mpa}$. Between 48 and 75 ' $\mathrm{C}$ we need to have initial pressure which are from 24 to $211 \mathrm{Mpa}$ to execute experiment. Moreover, with safety factor of 1.33 , from 22 to 52 ' $\mathrm{C}$ there is no need to incur launch pressure and maximum range is $178.5-248 \mathrm{Mpa}$. In contrast, from 52 to 80 ' $\mathrm{C}$ applying initial pressure is required that is start from about $25 \mathrm{Mpa}$ for $55^{\prime} \mathrm{C}$ and will be finished by 223 that is pertaining to $80^{\prime} \mathrm{C}$.

Actually the benefit of this means comparing others are:

Volume creep testing machine has been designed so that rock salt exposed by petroleum pressure. In this regard, making the equalized pressure on every point of the specimen. After filling the cell with petroleum and reaching the desired pressure, the movement part of check valve would be pulled towards the wall of cell and situated in its space in cell by cutting the petroleum stream from tank. Therefore, the inner pressure of cell will be preserved and we can claim that there are equal pressures on all parts of the specimen.

The clamps have been contrived so that they can follow the specimen. So, there is one spring inside of each bigger 
rod of clamp that has contact with the end of the smaller rod. Thus, during the experiment it pushes the smaller rod and hook. While rock salt is alleviating due to the petroleum pressure, the springs cause hooks trail and stick to the specimen.

In previous versions, one rubber sleeve had been contrived which located around the specimen and blocked the oil from reaching the sample. Therefore, it resulted in distancing the experiment away from the actual lifelike circumstance. In volume creep testing machine we made an opportunity to compare two different states including having and not having contact between salt and oil. To do this, two rubber sleeves have been contrived for two specimens that will be tested simultaneously. One of them is like previous and one of them is drilled that would help us achieve two specific goals such as:

- Preventing the specimen from falling apart as a result of excessive pressure.

- Helping the distinguished fluid (in this circumstance Petroleum) in reaching the specimen.

To increase the temperature of specimen and petroleum which are inside of the cell, we utilized a heater inside of the insulator such that has contact with outer lateral of cell but without any contacts with petroleum or specimen. The heater should locate inside of the insulator layer so that twist around the cell in order that it could heat the cell. Then this heat will be transmitted inside of the cell and increase the temperature of fluid and afterwards sample.

To save energy and preserve the pressure of petroleum inside of the cell during the experiment we changed and redesigned check valves after reaching to the desired pressure by cutting the pressure flow. To this respect, one platen closes the hole and retains the desired pressure.

Two frequent apparatus that have been used for measuring the strain during last thirty years were strain gauges and LVDTs which both of them are accurate and practical. Due to the fact that in volume creep test machine for the special condition of cell, using petroleum pressure to apply force to the specimen and isolated space of inside of the cell, as well as utilizing strain gauges or LVDTs are impossible. Therefore, we should substitute an effectual method to measure strain rate of the specimen from outside of the cell. Thus, ultrasonic wave propagation method has been chosen to measure strain rate and consequently processing the graph of creep. (At the end of this chapter there is a condensed explanation about how the ultrasonic test works).

- Economical

- Easy work

- Small and portable

\section{REFERENCES}

1. (Aghajani Kalkhouran, A Kind of Tracker Stabilizer System, 2016)

2. (Aghajani Kalkhouran, A New Design of Check Valve, 2016)

3. (Aghajani Kalkhouran, A creep testing machine, 2016)

4. (Aghajani Kalkhouran \& Jianfeng Xu, Design a Volume Creep Testing Machine for Testing Cylindrical Salt Rock Specimen Exposed by Petroleum Pressure, 2014)

5. (China Patent No. 201511018439.8, 2016) 
6. Park, B. D., and Balatinez, J. J. (1998). Short term flexural creep behavior of wood-fibre/polypropylene composites. Polym. Compos. 19, 377-382.

7. Shah, V. (2007). Handbook of Plastics Testing and Failure Analysis. Wiley.

8. Non-destructive Testing Center, T. H. (2012). Introduction to Non-Destructive Testing Techniques - Ultrasonic Testing.

9. Hoek, E. and Franklin, J.A. (1968). A simple triaxial cell for field and laboratory testing of rock. Trans. Instn Min. Metall. 77, A22- 26.

10. John A. Franklin and Evert Hoek. (1970). Developments in Triaxial Testing Technique. Rock Mechanics, Volume 2, $223-228$.

11. Bishop, A. W. and Henkel, D. J. (1957). The Measurement of Soil Properties in the Triaxial Test.

12. Blight, G. E. (1967) Effective Stress Evaluation for Unsaturated Soils, Soil Mechanics and Foundation Division. ASCE, Vol. 93 No. 2, $125-148$

13. Kenney, T. C. (1964). Pore pressure and bearing capacity of layered clays. J. Soil Mech. Fdns. Div. Am. Soc. Civ. Eng. 90, 2755.

14. Poulos, S. J. (1964). Control of Leakage in the triaxial test..Soil Mechanics Series No.71.Massachusetts Institute of Technology, Cambridge, MA.

15. Standard Specification for Perpendicularly Oriented Mineral Fiber Roll and Sheet Thermal Insulation for Pipes and Tanks, C1393 - 14.

16. Standard Test Methods for Conducting Creep, Creep-Rupture, and Stress-Rupture Tests of Metallic Materials, E 139-00.

17. Standard Test Method for Measuring the P-Wave Speed and the Thickness of Concrete Plates Using the Impact-Echo Method, C $1383-04$.

18. Standard Practice for Rubber and Rubber Latices-Nomenclature, D $141810 a$

19. Key to steel (software)

20. http://www.totalmateria.com

\section{COMPETING INTEREST SECTION}

This is Abbas AghajaniKalkhouran the author of this work declare that I have no competing interests.

I used president scholarship of Huazhong University of Science and Technology from 09/2013 until 06/2015. I applied for patent from the results of this work under title of “一种蠕变试验机” (A Creep Testing Machine) with application number: CN105403468A that is pending. And from the results of this work I published a book "A Creep Testing Machine "through Arna publishing with ISBN:978-600356-545-6 and its second edition published in 2016 with ISBN: 978-3-330-02611-7.

There are no any financial or non-financial competing interests (political, personal, religious, ideological, academic, intellectual, commercial or any other. 